\title{
Suscitando a Transferência de Conhecimento a Partir de Experiências em Sala de Aula com o Design de Brinquedos
}

\author{
Raising Knowledge Transfer from Classroom Experiences with Toy Design
}

OLIVEIRA, Jéssica Lane da Silva; Mestranda; Universidade de Brasília

jessicalaneoliveira@gmail.com

BOROON, Mahshid Ghasemi; Mestranda; Universidade de Brasília

mahshidgh.boroon@gmail.com

VIANA, Dianne Magalhães; DSc; Universidade de Brasília

diannemv@unb.br

KOIKE, Carla Maria Chagas e Cavalcante; DSc; Universidade de Brasília

ckoike@unb.br

JARDIM, Symone; MSc; Universidade de Brasília

symone.unb@gmail.com

\begin{abstract}
Resumo
Muito se discute acerca das competências exigidas para o século 21 e sobre modelos de ensino que podem fornecer uma aprendizagem adequada para a contemporaneidade. Neste cenário, destacam-se a aprendizagem baseada em problemas (PBL) e a integração de brinquedos ao ambiente de ensino, considerados também como material para a aprendizagem, especialmente das crianças. No entanto, pesquisas indicam que os brinquedos também podem ser pertinentes ao ensino de competências a jovens e adultos em diferentes áreas de conhecimento, incluindo o design. Nesse sentido, este trabalho apresenta uma revisão de literatura acerca do brinquedo e da sua utilização em processos de ensino-aprendizagem, e traz relatos de experiências envolvendo o uso de brinquedos como ferramenta de ensino no design, concluindo que esses artefatos possibilitam uma experiência de aprendizado significativa.
\end{abstract}

Palavras Chave: Competências do Século 21; Design de Brinquedos; PBL.

\begin{abstract}
There is much discussion about the skills required for the 21st century and on teaching models that can provide adequate learning for contemporaneity. In this scenario, problem-based learning (PBL) and the integration of toys into the teaching environment are also highlighted as materials for learning, especially for children. However, research shows that toys may also be relevant to teaching skills to young people and adults in different areas of knowledge, including design. In this sense, this work presents a literature review about the toy and its use in teaching-learning processes, and brings reports of experiences involving the use of toys as a teaching tool in design, concluding that these artifacts provide a relevant learning experience.
\end{abstract}

Keywords: 21st Century Skills; Toy design; PBL. 


\section{Introdução}

Muito se discute acerca das competências específicas para o século 21 e sobre os modelos de ensino que podem garantir uma aprendizagem significativa e adequada para a contemporaneidade. Neste cenário, destaca-se a aprendizagem baseada em problemas ( $\mathrm{PBL}$, do inglês Problem-Based Learning), que propõe um problema real motivador da aprendizagem, antes da discussão da teoria, e a integração de práticas e objetos lúdicos no ambiente de ensino, como jogos e brinquedos.

Com o advento da pedagogia, aliada aos estudos da psicologia do desenvolvimento, os brinquedos passaram a ser considerados também como material para a aprendizagem, e são utilizados ainda hoje para esse fim. Entretanto, seu uso em salas de aula se limita, de forma geral, a públicos infantis, ainda que sua utilização também tenha demonstrado validade no processo de ensino-aprendizagem de jovens e adultos.

Os brinquedos podem ainda ser utilizados como ferramentas no processo de ensinoaprendizagem do design em nível de graduação, garantindo a transferência e a aquisição de conhecimentos, assegurando uma aprendizagem significativa e desenvolvendo nos estudantes as competências do século 21, além de promover engajamento e motivação, quando utilizados dentro de uma abordagem da PBL, tema abordado neste trabalho.

Este artigo é composto, portanto, de uma revisão de literatura acerca da história do brinquedo e sua utilização em processos de ensino-aprendizagem, tanto como material quanto como ferramenta para a aquisição e transferência de conhecimento, e, por fim, apresenta relatos de experiências envolvendo o uso de brinquedos como ferramenta de ensino no design de produto, considerando sua pertinência nesse propósito.

\section{História do Brinquedo}

Os brinquedos acompanham as sociedades humanas há muitos séculos. Inicialmente confeccionados no seio dos grupos comunitários e familiares, os primeiros brinquedos eram produzidos a partir dos materiais naturais encontrados no ambiente ao redor, como galhos, argila, ossos, folhas, sementes e chifres de animais, por exemplo (BALEN-LETUNIĆ, 2004). Em escavações localizadas no distrito de Shirinsky, na Sibéria, onde viveram povos da cultura Okunev, arqueólogos encontraram oito estatuetas esculpidas em chifres, datadas da segunda metade do terceiro milênio a.C., que podem ter cumprido o papel de brinquedos, como pequenos chocalhos (POLYAKOV, ESIN, 2015).

Por muitos séculos, entretanto, o brinquedo foi um produto secundário de diversas oficinas manufatureiras, e não dispunha de comerciantes específicos para sua categoria. Foi apenas na segunda metade do século 19 que o brinquedo conquistou sua autonomia (BENJAMIN, 2002). Portanto, a industrialização tem um papel central na história dos brinquedos, que a partir de então, está intimamente relacionada às capacidades tecnológicas e produtivas, e avanços como novos materiais e técnicas de fabricação são decisivos para o nascimento de novos brinquedos.

Outro ponto decisivo na história dos brinquedos foi o advento da pedagogia, aliada aos estudos da psicologia do desenvolvimento, quando esses objetos passaram a ser considerados também como meios de facilitar a aprendizagem infantil. Um dos representantes desse fenômeno 
é Friedrich Fröebel, que desenvolveu a série de brinquedos Gifts, em 1837, com o objetivo de estimular o aprendizado através da brincadeira (COTRIM, RIBEIRO, 2014). Ainda hoje essa perspectiva se mantém firme, representada pelo mercado expressivo de brinquedos educativos: em 2017, brinquedos voltados a atividades intelectuais representaram 16,8\% das vendas no Brasil (ABRINQ, 2016).

A importância do brinquedo e do brincar para o desenvolvimento de capacidades físicas, cognitivas e psicossociais de crianças têm sido extensamente discutida e documentada em pesquisas de disciplinas como a Pedagogia e a Psicologia. Vygostky, por exemplo, discute as contribuições do brinquedo à estruturação do funcionamento psíquico da criança: para o autor, o brinquedo possibilita que a criança aprenda a agir cognitivamente, partindo de motivações e tendências internas, e não mais pelos incentivos oferecidos por objetos externos (ROLIM, GUERRA, TASSIGNY, 2008). Além disso, a brincadeira, apoiada pelos brinquedos, também pode facilitar as interações entre adultos e crianças e entre as próprias crianças, possibilitando o desenvolvimento e a reconstrução de conhecimento (ROLIM, GUERRA, TASSIGNY, 2008).

Entretanto, a relevância do brinquedo e do brincar no ensino-aprendizagem não se limita apenas às crianças. A diversão, a exploração e a liberdade oferecidas pelo brinquedo também podem ajudar adolescentes, jovens e adultos no processo de aprendizagem. Em uma pesquisa realizada com 22 alunos da modalidade de Ensino de Jovens e Adultos (EJA), Miranda (2015) avaliou a aplicação de jogos no ensino-aprendizado de Química, concluindo que o jogo pode auxiliar a prática educativa dos professores, ajudando-os a tornar as aulas mais dinâmicas e divertidas. A autora também observou que a idade não limitou o alcance do fator ludicidade, já que os sujeitos demonstraram engajamento, entusiasmo e interesse, tanto pelo jogo quanto pelo conteúdo abordado (MIRANDA, 2015).

Para além de sua utilização na área de Ciências, educadores de diferentes áreas também têm se apropriado dos brinquedos como recursos pedagógicos. Cruz, Couto e Ribeiro (2016), por exemplo, utilizaram brinquedos como meio para introduzir a tecnologia de fabricação digital a alunos de graduação em arquitetura e design.

Nessa perspectiva, além de objeto voltado à diversão, o brinquedo é também material de aprendizagem, permitindo aos brincantes que assimilem conhecimentos diversos durante a brincadeira. Entretanto, o brinquedo também pode ser usado de forma diferente no processo de ensino-aprendizagem: como uma ferramenta para a aquisição e transferência de conhecimento. Neste caso, os brincantes não assimilam conhecimentos ou habilidades através da brincadeira, mas sim, através do seu uso como um instrumento durante o processo de aprendizagem.

\section{O Design de Brinquedo como Ferramenta de Ensino-Aprendizagem}

A transferência de conhecimento é resultado de um processo de aprendizagem significativa, a partir da qual os estudantes adquirem a capacidade de tomar o que foi aprendido em uma situação e aplicar esses conhecimentos a novos cenários e diferentes contextos. Esses conhecimentos não se resumem a conteúdos de uma área específica, mas também incluem a habilidade de discernir como, porque e quando aplicar o conhecimento na resolução de problemas. A combinação desses conhecimentos e habilidades dá forma às competências do século 21, que incluem capacidades do campo cognitivo, como o pensamento crítico, a 
criatividade, a inovação e a argumentação; do campo intrapessoal, como a flexibilidade e a iniciativa pessoal; e do campo interpessoal, como a comunicação, a colaboração, a responsabilidade e a resolução de conflitos (PELLEGRINO, HILTON, 2012).

Os brinquedos já têm sido utilizados como ferramentas no ensino-aprendizagem e na transferência de conhecimento, especialmente em contextos relacionados à Ciência, Tecnologia, Arte, Engenharia e Matemática (STEAM). Nesse sentido, o projeto educativo CLOHE, financiado pela Comissão Europeia através do Lifelong Learning Program, utiliza brinquedos mecânicos como recurso para a aprendizagem de alunos do ensino básico, com o objetivo de desenvolver competências transversais, como a consciência cultural, a criatividade, a resolução de problemas e a sustentabilidade (BARGELLI, BARTOLETTI, 2012).

Relacionando o ensino do projeto em design a jogos e brincadeiras infantis, Serrasqueiro e Domiciano (2017) relatam a experiência de condução da disciplina "Projeto Lúdico", ofertada a alunos do 7ำ semestre do curso de Design Gráfico da Escola Superior de Administração, Marketing e Comunicação de Campinas (ESAMC). Durante a disciplina, foi solicitado aos alunos que desenvolvessem brinquedos para crianças de 05 a 07 anos, partindo da releitura de brincadeiras e jogos tradicionais, e utilizando o Método de Projeto de Archer. A estruturação da disciplina tinha como objetivo direcionar o aluno a uma formação crítica, estimulando a articulação de conceitos, configurações e processos técnicos envolvidos na elaboração do projeto, e propiciando a análise e a criação consciente dos objetos, capacidades que podem ser classificadas como competências do século 21.

Apesar de poucos relatos apresentados, o brinquedo tem se mostrado, até então, como uma ferramenta apropriada para a transferência de conhecimentos e para o ensino-aprendizagem de diferentes habilidades e capacidades, e em diferentes áreas de conhecimento - incluindo o design. Além de facilitar a aquisição de conteúdos, o brinquedo pode estimular atitudes criativas e ajudar a engajar os alunos durante o processo, assegurando uma aprendizagem significativa, a transferência de conhecimentos e o desenvolvimento de competências do século 21.

Considerando a pertinência do brinquedo para esse fim, partimos para um relato de experiências que envolvem a utilização de brinquedos como ferramentas no processo de ensinoaprendizagem e na transferência de conhecimentos em diferentes disciplinas, em especial o design de produtos.

\section{Relato de Experiências}

A abordagem de Kolb (1997) e a PBL (RIBEIRO, 2008) foram utilizadas para orientar o processo de ensino-aprendizagem das experiências relatadas. De acordo com a abordagem de Kolb, os aprendizes são levados a desenvolver tipos diferentes de habilidades, quais sejam: a de se envolver completa, aberta e imparcialmente em novas experiências; refletir sobre essas experiências e observá-las a partir de diferentes perspectivas; criar conceitos que integrem suas observações em teorias sólidas em termos de lógica; e usar essas teorias para tomar decisões e resolver problemas. Ao mesmo tempo, a PBL propõe um problema real motivador da aprendizagem, antes da discussão da teoria, e um método formal de solução que intercala trabalho em grupo com estudos independentes. Na PBL, uma sequência de problemas é estabelecida para o aprendizado de um assunto, e cada qual é abordado por vez. 
Aliado à abordagem de Kolb e à PBL, pressupõe-se que a interação entre conceitos e relações trazidas pelos estudantes, e as novas informações ou conceitos que precisam ser consolidados por meio das atividades de ensino, evoquem memórias e emoções que possam contribuir de forma positiva na motivação para a aprendizagem.

A primeira experiência relatada trata do projeto Automata, realizado no segundo semestre de 2014. Nesse projeto, uma turma formada por 12 estudantes de ensino médio, divididas em três equipes, foi solicitada a construiu brinquedos autômatos, com o objetivo de motivá-las a integrar as áreas de exatas, a partir de estudos em STEAM. Autômatos são brinquedos mecânicos e cinéticos que integram estética e movimento, podendo ser acionados de forma manual ou eletrônica, e sua confecção permite aos alunos a aquisição de conhecimentos de áreas como engenharia, mecânica, artes e design.

O segundo relato trata-se de várias experiências com a construção de brinquedos mecânicos, realizadas na disciplina Sistemas Mecânicos entre 2013 e 2017, envolvendo turmas de 10 a 15 estudantes. Os projetos foram desenvolvidos individualmente ou em equipes de dois ou três estudantes. A disciplina é obrigatória para estudantes de Design, da habilitação em Projeto de Produto.

O terceiro relato envolve o desenvolvimento de um projeto integrado de autômatos em dioramas, modelos de representação cênica tridimensional e cinética que também podem atuar como brinquedos, realizados em duas equipes interdisciplinares, cada qual formada por 10 estudantes dos cursos de Design, Engenharia Mecânica, Engenharia Mecatrônica e Ciência da Computação, ainda em andamento no primeiro semestre de 2018.

\subsection{O Projeto Automata}

O projeto consistiu na aplicação de um modelo PBL com um grupo de meninas de escola pública de periferia, no escopo do edital Meninas e Jovens Fazendo Ciência, do CNPq em parceria com a Petrobrás.

Como os desafios propostos demandavam conceitos de difícil execução autônoma em curto espaço de tempo, devido à distância dos conteúdos escolares, empregou-se o PBL híbrido apresentado por Ribeiro (2008) como suporte à resolução dos problemas, em módulos separados. A equipe responsável pelo projeto consistiu de duas professoras (de Engenharia Mecânica e de Artes) e cinco estudantes de graduação, sendo uma de Engenharia Mecânica, uma de Engenharia Elétrica, uma de Geofísica e duas de Arte, e uma estudante de pós-graduação em Sistemas Mecatrônicos.

O projeto se desenvolveu em duas fases, cada qual em um semestre letivo durante o ano de 2014. Na primeira fase, o objetivo era o aprendizado acerca de elementos básicos de mecânica e eletrônica, como alavancas, engrenagens, LEDs e motores, por métodos ativos e significativos. A segunda fase tinha por objetivo o desenvolvimento de brinquedos autômatos.

O papel das artes, que na primeira fase esteve presente de maneira auxiliar, com o intuito de tornar a aprendizagem lúdica, se tornou central e integrador na segunda fase, na qual os conhecimentos de outras áreas deveriam contribuir para a concretização dos projetos.

Como forma de motivação, no início da segunda fase foram apresentados exemplos de 
obras interativas, eletrônicas e/ou mecânicas que fizeram uso de materiais similares àqueles possíveis de aquisição, como tubos de PVC e papel machê.

Também foram propostos "diários de bordo" (Figura 1), cadernos sem pautas usados para fazer anotações das aulas práticas de mecânica e eletrônica, mas, principalmente, para registrar quaisquer ideias que surgissem ao longo dos estudos, fossem na forma escrita ou de desenho. Almejou-se incentivar o desenho como forma de registro, para facilitar a criatividade e alterar a noção de que a escrita seria mais importante para demonstração de uma ideia.

Foi estabelecido como tema o desenvolvimento projetos de brinquedos inspirados em animais. Como exercício de criatividade, foi desenvolvida uma dinâmica para que as alunas buscassem outras formas de criar os autômatos e não ficassem presas exclusivamente aos animais existentes. A partir de uma roda de conversa mediada pelas tutoras sobre criaturas fantásticas, imaginárias e híbridas, foram apresentados exemplos tanto de desenhos como de esculturas, com foco nos animais.

Em seguida, foram criadas quatro categorias de palavras (sendo a quarta opcional) para serem sorteadas:

1. Cerrado, floresta fechada, oceano profundo, deserto, lua, lago, ambiente urbano, mar, montanhas nevadas, cavernas;

2. Três rabos, duas bocas, quatro olhos, três orelhas, um olho só, sem pernas, quatro asas;

3. Chifres, escamas, casco, bigode, penas, bico, barbatanas, tromba, pelos, garras;

4. Possui duas sombras, dá leite achocolatado, toca música, produz eletricidade, brilha no escuro, cospe fogo, se alimenta de botões, é venenoso, solta laser, cospe ácido, parte do corpo biônica, se alimenta de narizes, só anda em grupo.

Figura 1 - Diário de bordo.

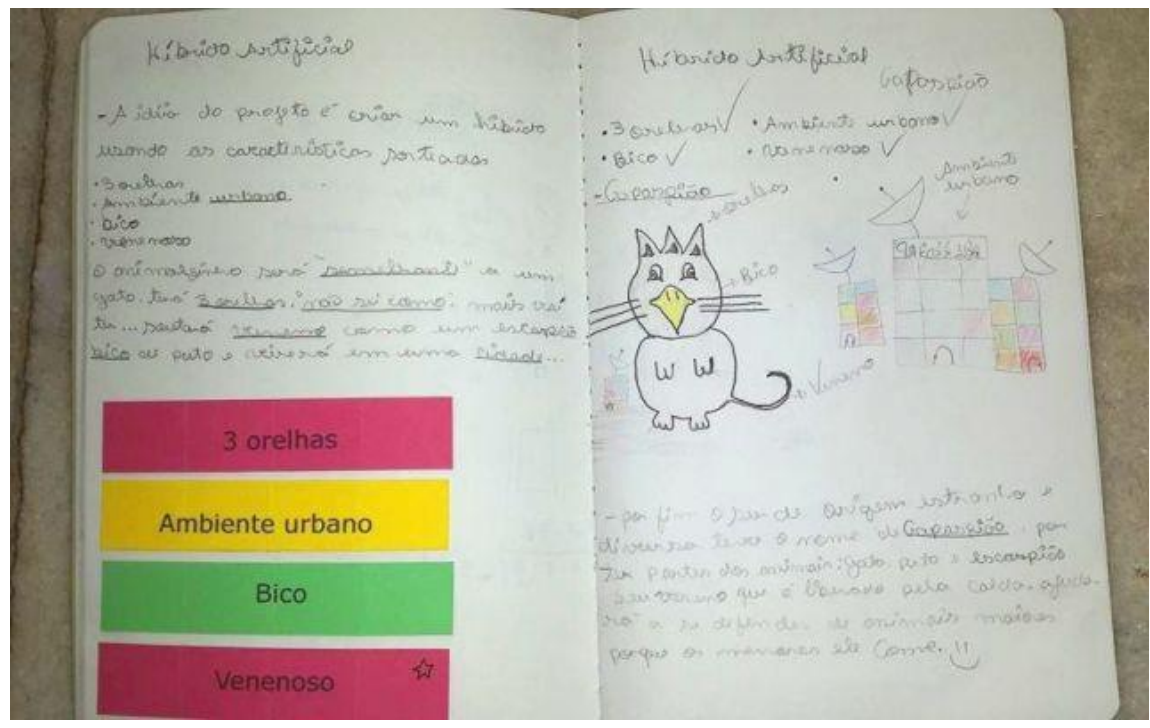

Fonte: As autoras.

Com o conjunto de elementos sorteados, as alunas deveriam elaborar uma criatura com tais características e escrever uma pequena biografia do híbrido criado, citando, por exemplo, do 
que ele se alimenta, como se locomove, etc.

A atividade se mostrou bastante motivadora. A maioria das alunas produziu mais de um desenho, e dali surgiram novas ideias para seus projetos, atendendo às expectativas com a abordagem proposta.

Dessa forma, a segunda fase do projeto foi dedicada à criação dos autômatos, e os módulos de ensino-aprendizagem passaram a integrar artes e escrita científica. Foram realizados exercícios de desenho criativo e observação, apresentadas alternativas de materiais artísticos e trabalhos de arte e tecnologia. As estudantes ficaram responsáveis pela produção integral de seus autômatos, desde a concepção artística à elaboração e superação de problemas.

A Figura 2 apresenta as etapas de desenvolvimento do projeto de um dos grupos, e a Figura 3 os protótipos de brinquedos autômatos.

Figura 2 - Ideação, concepção e construção do animal híbrido "gacovale".

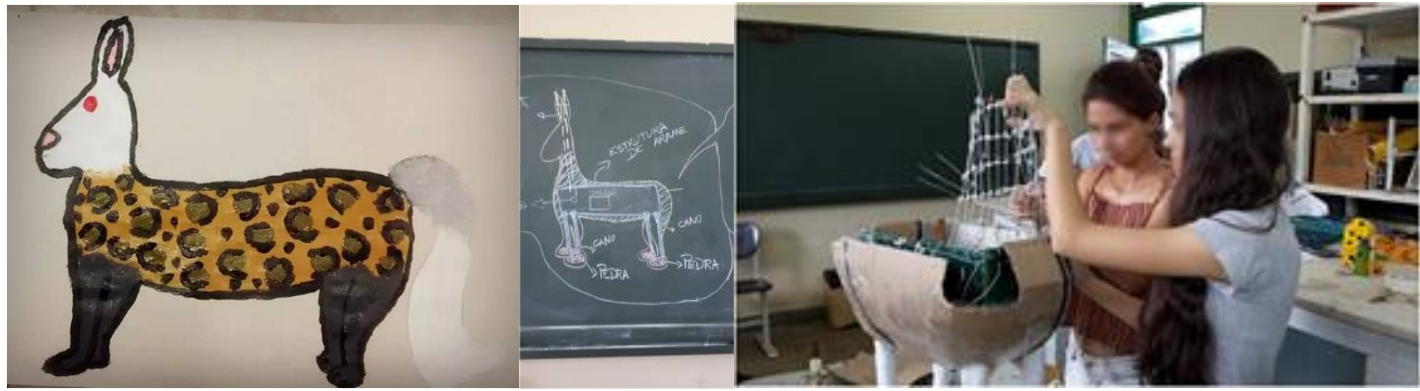

Fonte: As autoras.

Figura 3 - Animais híbridos: "cobreleta", "gapaspião" e "gacovale".
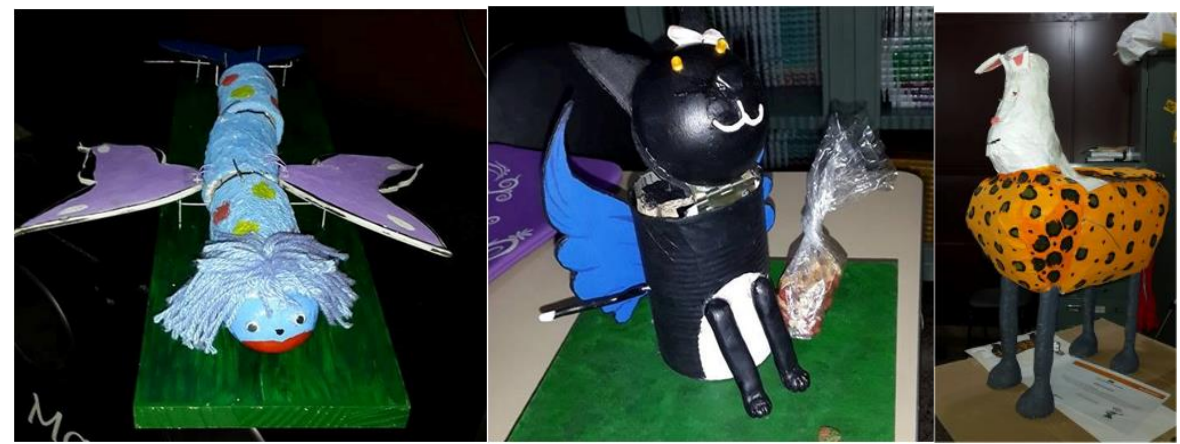

Fonte: As autoras.

\subsection{Disciplina de Sistemas Mecânicos}

Trata-se de uma disciplina de quatro créditos, ofertada pelo departamento de Engenharia Mecânica e obrigatória para a habilitação de Projeto de Produto do curso de Design da Universidade de Brasília. Os objetivos da disciplina consistem em desenvolver a capacidade de identificar e compreender mecanismos e componentes de máquinas usuais e suas aplicações, de forma a relacionar funcionalidades cinemáticas e de construção, requeridas no projeto de produtos, a esses mecanismos. Para que isso ocorra, é previsto o desenvolvimento de pelo menos 
um projeto de síntese envolvendo elementos estudados e/ou pesquisados pelos estudantes e a construção de protótipos.

A metodologia de ensino é baseada principalmente em aprendizagem ativa, representando cerca de $60 \%$ do conteúdo, e exposições curtas e interativas alternadas com situações envolvendo solução de problemas, representando $40 \%$ do conteúdo.

O tipo de aplicação do projeto a ser desenvolvido não é definido na ementa. A escolha pelo design de brinquedos é motivada pela possibilidade de relacionar a habilidade de resolver problemas considerando questões culturais, experiências e emoções pessoais, e competências cognitivas, intrapessoais e interpessoais, às competências técnicas trabalhadas, que envolvem escolher e projetar os mecanismos associados às partes móveis requeridas para que o produto desempenhe certa função.

A temática, o tipo de brinquedo e a faixa etária indicada, em geral, são fatores de livre escolha dos estudantes. $\mathrm{O}$ acionamento é sempre manual, com uso de manivelas. O projeto pode ser individual ou em equipe e o número de integrantes é levado em conta na análise dos resultados. Nas Figuras 4 a 6 são apresentados alguns projetos desenvolvidos pelos estudantes no escopo da disciplina.

\subsection{PrIA - Projeto Integrado de Autômatos}

O Projeto Integrado de Autômatos consiste de uma ação pedagógica ainda em andamento, envolvendo três disciplinas optativas de quatro créditos: Estudos em Computação, ofertada pelo curso de Ciência da Computação, Tópicos Especiais em Sistemas Mecânicos, ofertada pelo curso de Engenharia Mecânica e Tópicos Especiais em Design, ofertada pelo curso de Design. A experiência envolve um grupo de 20 estudantes, sendo dois da Ciência da Computação, cinco da Engenharia Mecânica, quatro da Engenharia Mecatrônica e nove do Design.

Figura 4 - Projetos envolvendo sistema de cames e transmissão por rodas de atrito: (a) Monstro do Mar; (b) e (c) Terra e Satélite.

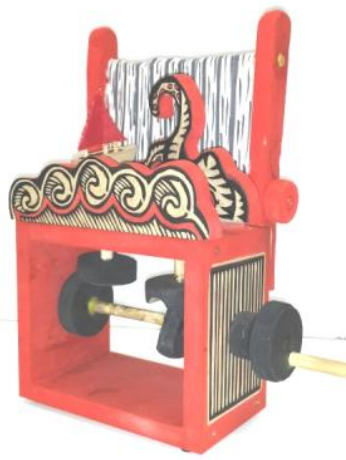

(a)

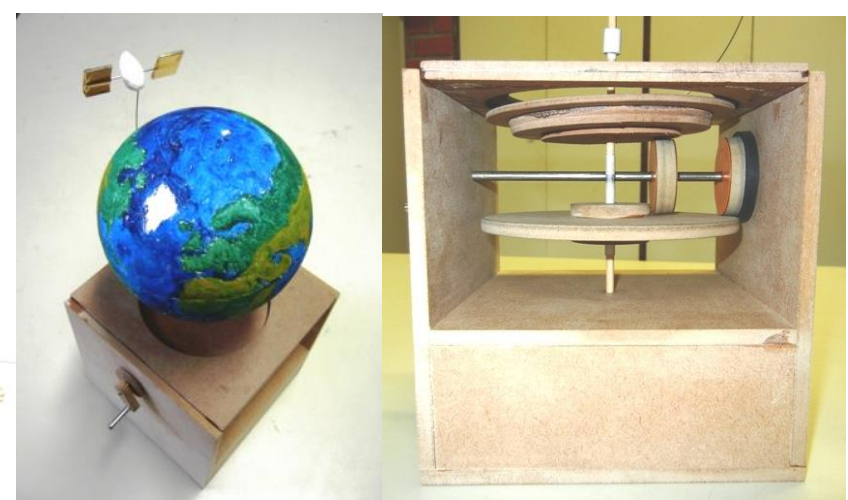

(b) (c)

Fonte: As autoras. 
Figura 5 - Projetos envolvendo sistema de cames e transmissão por polias: (a) e (b) Máquina de Bolinhas de Gude; (c) Vitrola.

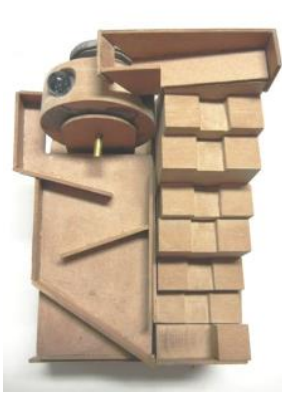

(a)

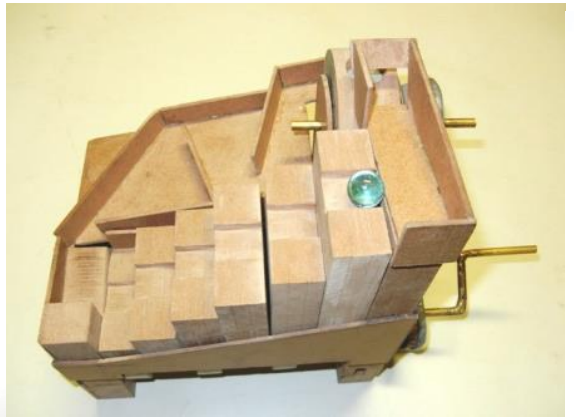

(b)

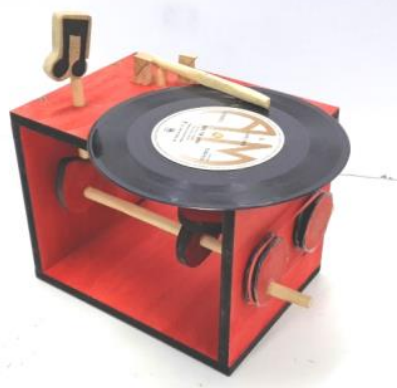

(c)

Fonte: As autoras.

Figura 6 - Projetos envolvendo sistemas de cames e transmissões por engrenagens: (a) e (b) Fundo do Mar; (c) Ponte Levadiça; (d) e (e) Bateria do Linkin Park; (f) Come-Come.

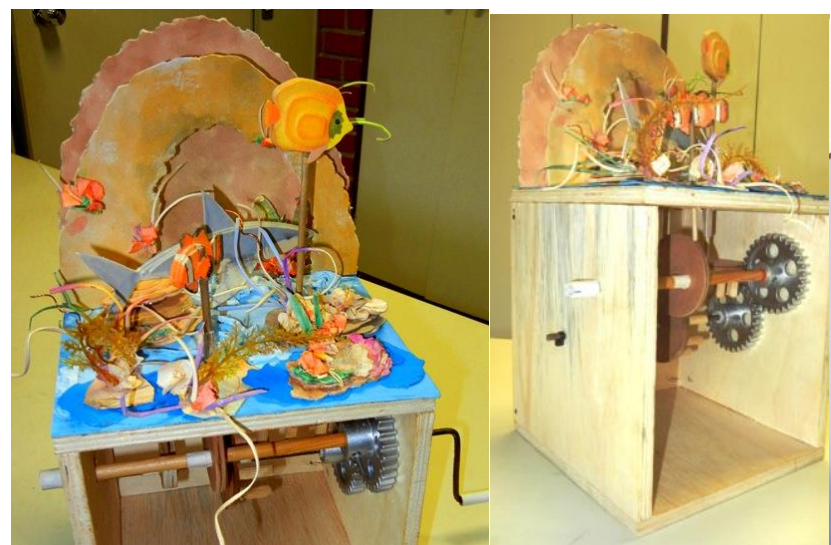

(a) (b)

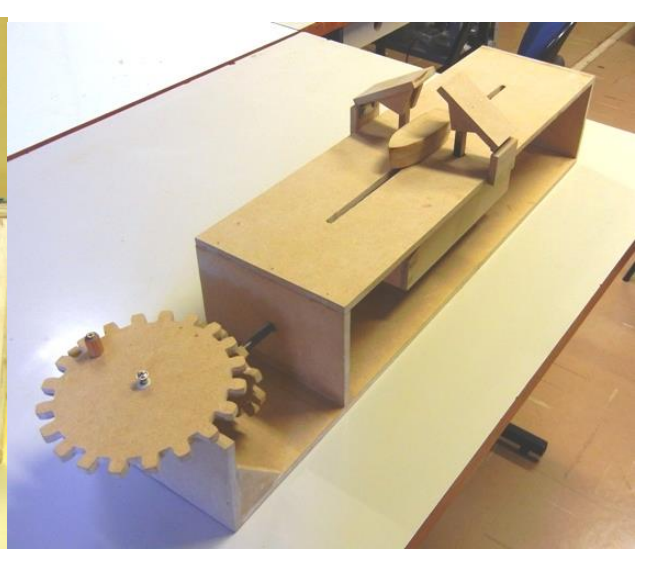

(c)

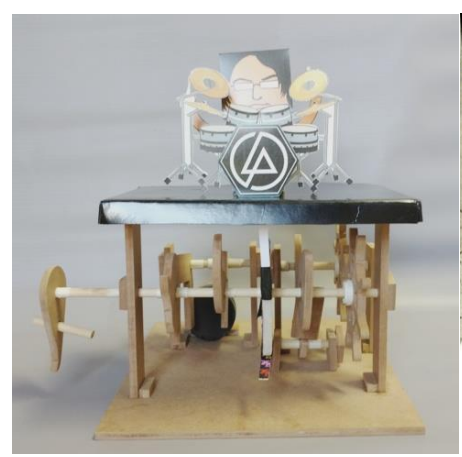

(d)

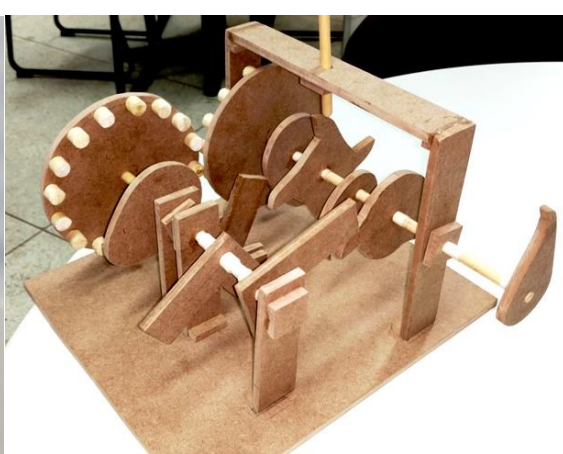

(e)

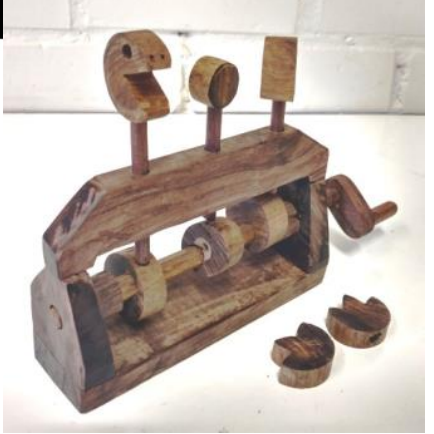

(f)

Fonte: As autoras.

A proposta consiste em proporcionar aos estudantes a oportunidade de desenvolver projetos e construir dioramas dinâmicos integrando equipes interdisciplinares. Para isso, a turma 
foi dividida em dois grupos, distribuindo de forma equivalente os estudantes de cada área. Além das professoras das disciplinas há dois tutores para apoiar os grupos.

A metodologia de ensino-aprendizagem é híbrida, e os principais aspectos relacionados à sua execução são apresentados na Tabela 1 . Também são avaliados aspectos relacionados à efetividade do uso de tecnologias da informação e comunicação durante a fase de desenvolvimento do projeto, em que os estudantes ficam dois períodos de duas semanas sem reuniões presenciais. Também nessa fase são realizadas inserções de conhecimentos técnicos a serem apropriados na construção dos dioramas, que envolvem temas como sistemas mecânicos, automação, prototipagem e gestão de projetos, prevalecendo métodos ativos de aprendizagem.

Tabela 1 - Planejamento do experimento pedagógico de integração de disciplinas.

\begin{tabular}{|c|c|c|c|}
\hline & Evento & Metodologia & Competências trabalhadas \\
\hline Semana 1 & Integração dos participantes & Roda de conversa & $\begin{array}{l}\text { Fala e escuta ativa - interpessoais e } \\
\text { intrapessoais; }\end{array}$ \\
\hline Semana 2 & $\begin{array}{l}\text { "Procurando uma temática" } \\
\text { para ser executada em um } \\
\text { diorama dinâmico }\end{array}$ & $\begin{array}{l}\text { Brainstorming/ Mapa } \\
\text { mental }\end{array}$ & $\begin{array}{l}\text { Criatividade, comunicação - } \\
\text { cognitivas e interpessoais; }\end{array}$ \\
\hline Semana 3 & $\begin{array}{l}\text { "Traduzindo movimentos por } \\
\text { meio de mecanismos" }\end{array}$ & PBL & $\begin{array}{l}\text { Autonomia, resolução de problemas, } \\
\text { pensamento crítico, visão espacial, } \\
\text { representação gráfica, comunicação - } \\
\text { cognitivas e interpessoais; }\end{array}$ \\
\hline Semana 4 & Conceituação e planejamento & $\begin{array}{l}\text { Metodologia de projeto } \\
\text { de produto }\end{array}$ & $\begin{array}{l}\text { Pensamento crítico, visão espacial, } \\
\text { escrita - cognitivas e intrapessoais; }\end{array}$ \\
\hline Semana 5 & $\begin{array}{l}\text { Apresentação da proposta de } \\
\text { diorama dinâmico }\end{array}$ & $\begin{array}{l}\text { Apresentação/ } \\
\text { Feedback }\end{array}$ & $\begin{array}{l}\text { Apresentação oral, comunicação - } \\
\text { cognitivas e interpessoais; }\end{array}$ \\
\hline $\begin{array}{lll}\text { Semana } & 6 & a \\
14 & & \end{array}$ & Desenvolvimento do projeto & PBL & $\begin{array}{l}\text { Técnicas e não técnicas: colaboração, } \\
\text { raciocínio lógico, comunicação, } \\
\text { manuseio de tecnologias digitais, } \\
\text { criatividade, controle do tempo - } \\
\text { cognitivas, intrapessoais e } \\
\text { interpessoais; }\end{array}$ \\
\hline Semana 15 & $\begin{array}{l}\text { Apresentação final e } \\
\text { demonstração do produto }\end{array}$ & $\begin{array}{l}\text { Apresentação/ } \\
\text { Avaliação de } \\
\text { especialistas/ Avaliação } \\
\text { de pares }\end{array}$ & $\begin{array}{l}\text { Apresentação oral, comunicação - } \\
\text { cognitivas e interpessoais. }\end{array}$ \\
\hline
\end{tabular}

Fonte: As autoras.

A abordagem PBL adotada na Semana 3 se baseou nos passos propostos por Ribeiro (2008), sendo a questão do problema "Como traduzir os movimentos do diorama por meio de mecanismos?" trabalhada em dois encontros presenciais (Figura 7):

Encontro 1: 
1) Introdução e definição do problema: Esboço do cenário relacionado ao tema;

2) Levantamento de hipóteses: onde serão as partes móveis? Qual o tipo de movimento?

3) Tentativa de solução com os conhecimentos disponíveis: cada um elabora propostas de mecanismos para realizar o movimento;

4) Levantamento de pontos de aprendizagem: Como integrar os movimentos? Que mecanismos podem ser usados? A estrutura do cenário sofrerá alterações?

5) Planejamento do trabalho do grupo;

Extraclasse:

6) Estudo independente; Pesquisa de outros mecanismos que poderiam ser usados alternativamente aos que foram propostos;

Encontro 2:

7) Compartilhamento de informações com o grupo;

8) Análise de alternativas; Trocas de experiências sobre as alternativas encontradas;

9) Apresentação das soluções do grupo.

A Semana 3 conclui a fase inicial de integração e exploração de ideias sem a sistematização do processo de projeto. Assim, é prevista uma avaliação neste momento, cujos resultados devem ser comparados com os resultados finais.

Figura 7 - Momentos do PBL: Trabalho individual, compartilhamento de informações e apresentação das soluções do grupo.
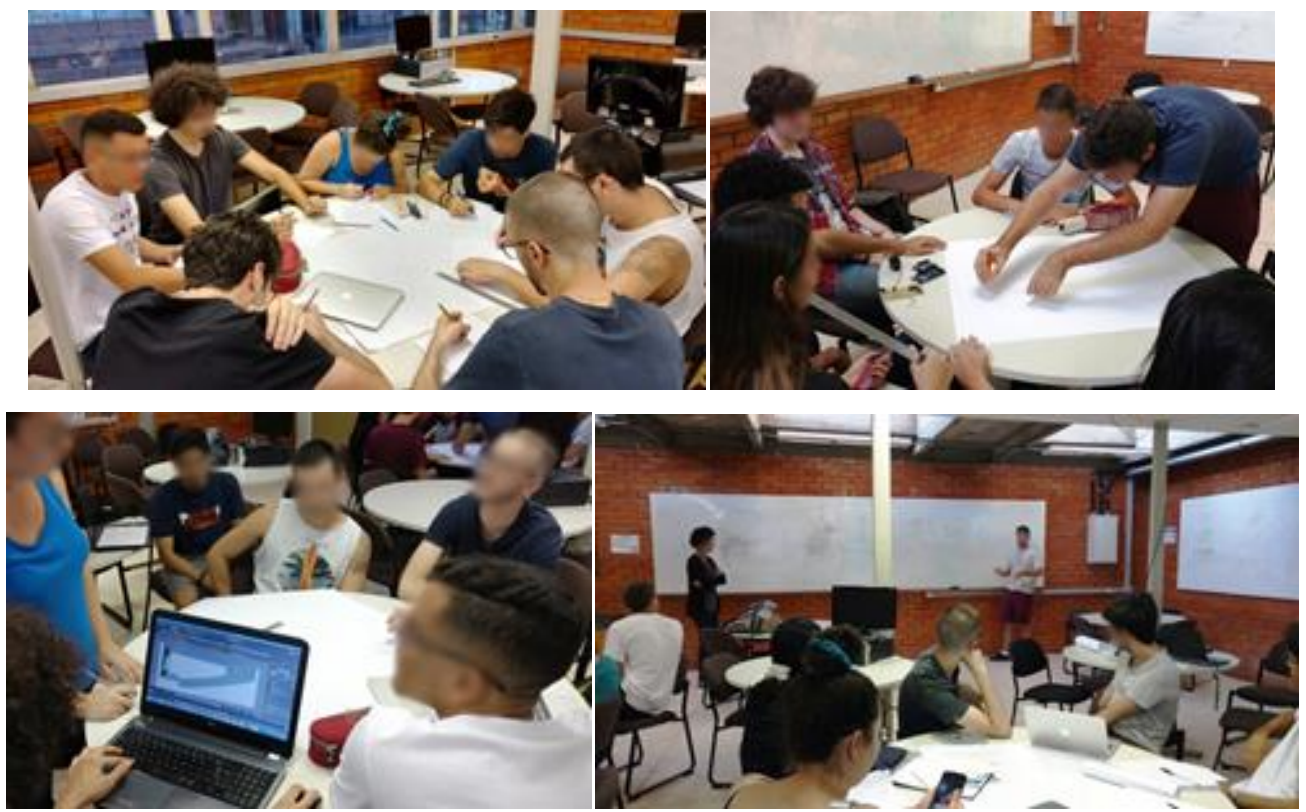

Fonte: As autoras. 


\section{Considerações Acerca das Experiências Realizadas}

As três experiências relatadas neste trabalho sugerem que a utilização de brinquedos como ferramenta no processo de ensino-aprendizagem, aliados a metodologias de ensino como a PBL, permite aos alunos jovens e adultos a aquisição de conhecimentos relevantes a suas áreas de estudo, bem como de competências pertinentes ao contexto contemporâneo, como o pensamento crítico, a colaboração em trabalhos em grupo, o raciocínio lógico, a comunicação, o controle de tempo, e a criatividade, além de promoverem maior engajamento e motivação dos estudantes.

Além disso, quando utilizados como tema no desenvolvimento de projeto de produtos dentro de disciplinas voltadas ao design, os brinquedos exigem dos estudantes que voltem seu olhar a um público e tipo de produto com demandas específicas, relacionadas a diferentes áreas do conhecimento. Ao projetar brinquedos, os alunos precisam considerar aspectos como a segurança, a ergonomia, a estética, a prática e a cultura lúdica do público infantil, aliando-os a exigências produtivas, mecânicas e estruturais. Desta forma, os estudantes são instigados a considerar o projeto de forma holística, o que possibilita uma rica e significativa experiência de aprendizado integral.

Os protótipos apresentados pelos alunos ao final das experiências apresentadas revelam também que o uso dos brinquedos como ferramenta em sala de aula facilita o processo de transferência de conhecimento, capacitando-os a aplicar adequadamente os conteúdos aprendidos em sala de aula aos problemas propostos pelos projetos acadêmicos.

\section{Considerações Finais}

Usualmente associados ao lazer, à brincadeira e à diversão, os brinquedos são artefatos multifuncionais, dependendo do contexto em que são utilizados: quando entregues às crianças, podem promover brincadeiras; quando descansam em prateleiras de colecionadores, são objetos de enorme valor sentimental e simbólico; quando integram acervos de museus, são artefatos históricos repletos de conteúdo cultural; e quando são levados às salas de aula, podem promover o ensino e a aprendizagem significativa de diferentes competências.

Teóricos como Jean Piaget, Lev Vygotsky e Friedrich Fröebel há muito argumentaram a favor dos brinquedos como estímulo à aprendizagem e ao ensino, perspectiva que se sustenta ainda hoje, especialmente na pedagogia direcionada às crianças. No entanto, pesquisas contemporâneas demonstram que o potencial educativo dos brinquedos alcança também jovens e adultos, ainda que esses objetos tenham deixado de integrar o cotidiano desses indivíduos. Nesse sentido, o brinquedo tem se mostrado como material apropriado para o ensino-aprendizagem de diferentes conhecimentos, e em diferentes áreas.

No ensino e aprendizagem do design, em nível de graduação, a utilização dos brinquedos como ferramenta de ensino ou tema de projetos avaliativos, especialmente quando associada à metodologia PBL, também demonstra grande potencial educacional para jovens e adultos, como apontado pelas referências citadas neste trabalho e pelas experiências relatadas. Os brinquedos exigem dos estudantes que voltem seu olhar a um público e tipo de produto com demandas 
específicas, relacionadas a diferentes áreas do conhecimento, possibilitando uma rica e significativa experiência de aprendizado integral, e facilitando o processo de transferência de conhecimento, capacitando futuros designers a aplicar adequadamente os conteúdos adquiridos durante sua formação a projetos dentro e fora das salas de aula.

Deste modo, o resgate dos brinquedos para as salas de aula de design demonstra-se pertinente para a formação holística de estudantes e profissionais da área, assegurando a aquisição de conhecimentos técnicos e de competências cognitivas, intrapessoais e interpessoais exigidas pela contemporaneidade.

\section{Referências}

ASSOCIAÇÃO BRASILEIRA DOS FABRICANTES DE BRINQUEDOS (ABRINQ). Brinquedos 2017 Estatísticas. São Paulo, 2016.

BARGELLI, L.; BARTOLETTI, C. Moving Automata Toys in the classroom: a multifaceted didactical pathway. Borgorete Società Cooperativa Sociale, Perugia (Italy). In: International Conference The Future of Education, Florença, 07 a 08 jun. 2012. Proceedings of International Conference The Future of Education, 2012.

BALEN-LETUNIĆ, D. An overview of prehistoric toys. In: Etnološka istraživanja, v. 1, n. 18/19, p. 11-17, outubro 2004.

BENJAMIN, W. Reflexões sobre a criança, o brinquedo e a educação. 34 ed. São Paulo: Duas Cidades, 2002.

COTRIM, M. A. P.; RIBEIRO, R. Design e infância: projetando para brincar. In: Congresso Brasileiro de Pesquisa e Desenvolvimento em Design, v. 1, n. 4, Gramado, 29 set. a 02 out. Anais do 11 o Congresso Brasileiro de Pesquisa e Desenvolvimento em Design. São Paulo: Blucher, 2014. p. 444456.

CRUZ, G. F. S.; COUTO, M. S.; RIBEIRO, F. N. F. Brinquedos óticos animados e o ensino de design. In: Congresso Brasileiro de Pesquisa e Desenvolvimento em Design, v. 9, n. 2, Belo Horizonte, 04 a 07 out. 2016. Anais do 12 Congresso Brasileiro de Pesquisa e Desenvolvimento em Design. São Paulo: Blucher, 2016. p. 2236-2247.

MIRANDA, A. F. S. Jogos Pedagógicos no Processo de Ensino e Aprendizagem em Química na Modalidade Educação de Jovens e Adultos. 2015. Dissertação (Mestrado em Educação em Ciências e Matemática) - Programa de Pós-Graduação em Educação em Ciências e Matemática, Universidade Federal de Goiás, Goiânia.

PELLEGRINO, J. W.; HILTON, M. L. (Ed). Education for life and work: Developing transferable knowlege and skills in the 21st century. Washington: The National Academies Press, 2012.

POLYAKOV, A. V.; ESIN, Y. N. Horn figurines from an Okunev burial on Lake Itkul, Khakassia, Southern Siberia. In: Archaeology, Ethnology and Anthropology of Eurasia, v. 43, n.o 2, p. 43-57, 2015.

RIBEIRO, L. R. de C. Aprendizagem Baseada Em Problemas (PBL) Na Educação Em Engenharia. In: Revista de Ensino de Engenharia, v. 27, n. 2, p. 23-32, 2008. 
ROLIM, A. A. M.; GUERRA, S. S. F.; TASSIGNY, M. M. Uma leitura de Vygotsky sobre o brincar na aprendizagem e no desenvolvimento infantil. In: Humanidades, v. 23, n.o 02, p. 176-180, jul/dez 2008.

SERRASQUEIRO, V. B.; DOMICIANO, C. L. C. Releituras lúdicas aplicadas ao público infantil: notas sobre uma experiência projetual no ensino de design. In: Congresso Brasileiro de Pesquisa e Desenvolvimento em Design, v. 9, n. 2, Belo Horizonte, 04 a 07 out. 2016. Anais do 120 Congresso Brasileiro de Pesquisa e Desenvolvimento em Design. São Paulo: Blucher, 2016. p. 2915-2925. 